\title{
Study of lipid peroxidation and ascorbic acid protective role in large unilamellar vesicles from a new electrochemical performance
}

\author{
M. Fátima Barroso ${ }^{\mathrm{a}, *}$, M. Alejandra Luna ${ }^{\mathrm{b}}$, Fernando Moyano ${ }^{\mathrm{b}}$, Cristina Delerue-Matos ${ }^{\mathrm{a}}$, \\ N. Mariano Correa ${ }^{\mathrm{b}}$, Patricia G. Molina ${ }^{\mathrm{b}, * *}$ \\ a REQUIMTE/LAQV/Instituto Superior de Engenharia do Porto, Instituto Politécnico do Porto, Rua Dr. António Bernardino de Almeida, 431, 4200-072 Porto, Portugal \\ b Departamento de Química, Universidad Nacional de Río Cuarto. Agencia Postal \# 3, C.P. X5804BYA Río Cuarto, Argentina
}

\begin{abstract}
In this contribution an electrochemical study is described for the first time of lipid peroxidation and the role of antioxidant on lipid protection using large unilamellar vesicles (LUVs). In order to simulate the cell membrane, LUVs composed of 1,2-dioleoyl-sn-glycero-3-phosphocholine (DOPC) were used. A vesicle-modified electrode was constructed by immobilizing DOPC LUVs onto carbon paste electrodes (CPEs). Lipid peroxidation was studied electrochemically by incubating the vesicle-modified electrodes with hydroxyl $(\mathrm{HO} \cdot)$ radicals generated via the Fenton reaction. Oxidative damage induced by $\mathrm{HO} \bullet$ was verified by using square wave voltammetry (SWV) and was indirectly measured by the increase of electrochemical peak current to $\left[\mathrm{Fe}(\mathrm{CN})_{6}\right]^{4-}$ which was used as the electrochemical label. Ascorbic acid (AA) was used as the antioxidant model in order to study its efficacy on free radical scavenging. The decrease of the electrochemical signal confirms the protective key role promoted by AA in the prevention of lipid peroxidation in vesicles. Through microscopy, it was possible to observe morphologic modification on vesicle structures after lipid peroxidation in the presence or absence of AA.
\end{abstract}

Keywords:

Vesicles

Lipid peroxidation

Antioxidant

Ascorbic acid

Electrochemistry

\section{Introduction}

Oxidant compounds (radicals and non-radicals) are a consequence of normal aerobic metabolism, being continuously generated in living cells (in the inner and outer mitochondrial membrane) and in several metabolic pathways in mammalian cells (microsomal electron transport) [1]. These strong oxidants are able to induce damage in cells by reacting with biomolecules, namely proteins, lipids, DNA and carbohydrates, amongst others, causing a negative effect on intra- and extracellular signal transmission [2].

Although the oxidative lesions in DNA are the primary risk factor for gene mutations, which play a key role in carcinogenesis and aging [3,4], currently, lipid peroxidation is considered as the main molecular mechanism involved in oxidative damage to cell structures and in the toxicity process that leads to cell death [5].

Lipid peroxidation is the oxidative damage induced by free radicals to the hydrophobic parts of the biological cellular membrane [6], and involves three distinct steps: i) initiation; ii) propagation iii) termination [7]. The initiation step occurs when free radicals $(R \cdot)$ (namely reactive oxygen species (ROS), such as ${ }^{1} \mathrm{O}_{2} ; \mathrm{O}_{2}{ }^{\bullet-}$ or $\mathrm{HO} \bullet$ ) react with a lipid substrate ( $\mathrm{LH})$ or when a breakdown of a pre-existing lipid hydroperoxides (LOOH) takes place caused by transition metals (Eq. (1)). In both cases a highly reactive lipid radical $\left(\mathrm{L}^{\bullet}\right)$ is generated [8]. The second phase, in the propagation of lipid peroxidation (Eqs. (2) and (3)), molecular oxygen reacts quickly with $\mathrm{L} \cdot$ to produce the lipid peroxyl radical (LOO•). LOO• has the ability to remove a hydrogen atom from DNA and proteins, producing a lipid hydroperoxide ( $\mathrm{LOOH})$. In the termination phase, two lipid radicals react to produce a non-radical species (Eqs. (4)-(6)) [9]. Amongst the degradation products of ROOH are aldehydes, such as malondialdehyde, and hydrocarbons, such as ethane and ethylene, which are the commonly measured end products of lipid peroxidation [10].

Initiation

$\mathrm{LH}+\mathrm{R} \cdot \mathrm{L} \cdot \mathrm{RH}$

Propagation

$\mathrm{L}^{\cdot}+\mathrm{O}_{2} \rightarrow \mathrm{LOO}$ 
$\mathrm{LOO}^{*}+\mathrm{LH} \rightarrow \mathrm{LOOH}+\mathrm{L}^{*}$

Termination

$\mathrm{LOO}^{*}+\mathrm{LOO}^{\rightarrow} \rightarrow \mathrm{LOOL}+\mathrm{O}_{2}$

$\mathrm{L}^{\cdot}+\mathrm{L}^{\prime} \rightarrow \mathrm{L}-\mathrm{L}$

$\mathrm{LOO}^{*}+\mathrm{L}^{\cdot} \rightarrow \mathrm{LO}-\mathrm{OL}$

To counteract and prevent the oxidative damage induced by these compounds, living organisms have developed complex endogenous and exogenous antioxidant systems. According to Laguerre et al. (2010) a biological antioxidant is a compound which, when present at low concentration compared to an oxidizable substrate, protects (by itself and through its oxidation products) that substrate from oxidation, and ultimately protects the organism from the harmful effects of oxidative stress (Eqs. (7)-(9) [11]. Endogenous antioxidants include enzymes, small molecular compounds, and cofactors [12,13]. Additional protection can be provided by exogenous antioxidant compounds, which are present in foodstuffs and beverages.

$\mathrm{L}^{\cdot}+\mathrm{HX}($ antioxidant $) \rightarrow \mathrm{LH}+\mathrm{X}^{\cdot}$

$\mathrm{LOO}+\mathrm{HX} \rightarrow \mathrm{LOOH}+\mathrm{X}$

$\mathrm{X} \cdot \mathrm{X} \rightarrow \mathrm{X}-\mathrm{X}$

Several procedures have been reported for the evaluation of the effects of radicals and antioxidants on cellular biomolecules, namely based on UV-vis spectrometry, chemiluminescence, chromatography and electrochemistry [14-16]. Amongst these, the use of electrochemical devices is seen to be the best of all because interactions between radicals, antioxidants and biomolecules are based on electron transfer reactions which can be easily monitored by the methodology [1]. Hu and collaborators used amperometric techniques at platinized carbon fiber electrodes to monitor and characterize the quantity of radicals (e.g. $\mathrm{NO} \cdot, \mathrm{ONOO}^{-}, \mathrm{NO}_{2}, \mathrm{H}_{2} \mathrm{O}_{2}$ and $\mathrm{O}_{2}{ }^{-}$) released by $\mathrm{MG63}$ osteosarcoma cells. The electrochemical procedure proved that the malignant bone formation ability of osteosarcoma cells was related to the specific high production of $\mathrm{NO} \cdot$ associated with a small production of $\mathrm{O}_{2}{ }^{-}$.

Some reports indicate the use of voltammetric techniques for the visualization of the oxidative damage induced by radicals such as hydroxyl, sulfate and superoxide at DNA layers immobilized on gold or carbon surfaces [2]. However, as far as we know, there are no electrochemical studies concerning the effect of hydroxyl radicals on phospholipid bilayers present in the large unilamellar vesicles (LUVs), as cellular membrane simulation, which can be adsorbed onto transducer surfaces.

This work describes, for the first time, the construction and optimization of a vesicle modified electrode designed to measure lipid peroxidation induced by hydroxyl radicals ( $\mathrm{HO} \bullet$ ) generated via the Fenton reaction (Eq. (10)).

$\mathrm{Fe}^{2+}+\mathrm{H}_{2} \mathrm{O}_{2} \rightarrow \mathrm{Fe}^{3+}+\mathrm{HO}-+\mathrm{HO}^{-}$

The vesicle-modified electrode consisted of an adsorptive immobilization of LUVs of 1,2-dioleoil-sn-glicero-3-fosfatidilcoline (DOPC), onto a carbon paste electrode (CPE) surface. The antioxidant ascorbic acid (AA) was evaluated for its protective effect against $\mathrm{HO}^{\circ}$ radicals on the vesicles immobilized on the $\mathrm{CPE}$. Electrochemical measurements were carried out by using square wave voltammetry (SWV) and cyclic voltammetry (CV): dynamic light scattering (DLS) and transmission electron microscopy (TEM) were also used in order to observe the morphologic changes after vesicles peroxidation. This study offers a basic understanding of lipid peroxidation and the protective role of antioxidants using electrochemical and microscopic techniques.

\section{Experimental}

\subsection{Chemical and solutions}

The lipid 1,2-di-oleoyl-sn-glycero-3-phosphatidylcholine (DOPC in chloroform solution) was obtained from Avanti Polar Lipids, Inc. (Alabaster Al, USA) and used without further purification. Ascorbic

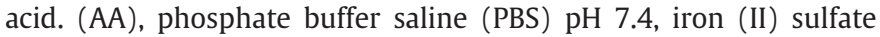
heptahydrate, hydrogen peroxide $(30 \%, \mathrm{w} / \mathrm{v})$, potassium ferrocyanide, ethylenediamine tetraacetic acid (EDTA), $1(+)$-Ascorbic acid were from Merck. All chemicals employed were used without further purification.

The Fenton mixture (generation of hydroxyl radical) was prepared by mixing $\mathrm{Fe}^{2+}$ : EDTA: $\mathrm{H}_{2} \mathrm{O}_{2}\left(1 \mathrm{~mol} \mathrm{l}^{-1}: 2 \mathrm{~mol} \mathrm{l}^{-1}: 40 \mathrm{~mol} \mathrm{l}^{-1}\right)$ in a molar ratio of 1:2:40 [17]. EDTA was added for solubility reasons. All solutions were prepared with water purified with a Direct-Q (Millipore) system.

\subsection{Instrumentation}

An Autolab PGSTAT 30 potentiostat, controlled by GPES 4.8 software, was employed for the cyclic (CV) and square wave voltammetry (SWV) measurements. Cyclic voltammograms were obtained at $100 \mathrm{mV} \mathrm{s}^{-1}$. The characteristic parameters used to obtain square wave voltammograms were $\mathrm{SW}$ amplitude $\left(\Delta \mathrm{E}_{S W}\right) 0.025 \mathrm{~V}$; the staircase step height $\left(\Delta E_{s}\right) 0.005 \mathrm{~V}$ and the frequency (f) $20 \mathrm{~Hz}$. A carbon paste electrode (CPE) composed by activated carbon (50\%), ricine oil (30\%) and nafion (20\%) was used as working electrode (geometric area $=0.030 \mathrm{~cm}^{2}$ ). The CPE electroactive area was calculated from convoluted CVs [18].

The following mathematical expression was applied for this calculation

$\mathrm{I}_{\mathrm{L}, \mathrm{con}}=\mathrm{nFAD}^{1 / 2} \mathrm{C}^{*}$

where $\mathrm{I}_{\mathrm{L}, \mathrm{con}}$ is the convoluted limiting current, $\mathrm{n}$ is the number of electrons exchanged by the ferrocyanide compound $(\mathrm{n}=1), \mathrm{F}$ is the Faraday constant $\left(96,464 \mathrm{C} \mathrm{mol}^{-1}\right), \mathrm{A}$ is the electroactive surface area $\left(0.0525 \mathrm{~cm}^{2}\right), \mathrm{D}$ is the diffusion coefficient of the electroactive species (in this case $7.6 \times 10^{-6} \mathrm{~cm}^{2} \mathrm{~s}^{-1}$ ) [19] and $\mathrm{C}$ is the molar concentration of redox specie $\left(4.0 \times 10^{-6} \mathrm{~mol} \mathrm{~cm}^{-3}\right)$.

The unmodified carbon paste was introduced into the well of a Teflon electrode body and its surface was smoothed against plain white paper while slight manual pressure was applied to the electrode. Unless otherwise stated, after each experiment, the carbon paste was discarded and a new electrode surface was freshly prepared. The counter electrode was a Pt foil of large area $\left(2 \mathrm{~cm}^{2}\right)$ and a $\mathrm{Ag} / \mathrm{AgCl}$ wire was used a pseudo reference electrode and periodically monitored against a saturated calomel electrode.

The diameters of the DOPC vesicles, namely the large unilamellar vesicles (LUVs) were determined by dynamic light scattering (DLS) by using a Malvern 4700 analyser with a goniometer, a 7132 correlator, and an argon-ion laser operating at $488 \mathrm{~nm}$. All measurements were made at a scattering angle of $90^{\circ}$ at a temperature of $20 \pm 0.1^{\circ} \mathrm{C}$.

Transmission electron microscope (TEM) micrographs was obtained using a Siemens (Germany) Jeol - Jem 1200 EX II (Elmiskop 101) P at 20-120 kV with a Megaview-II Docu camera and SIS NT Docu software.

Approximately $20 \mu \mathrm{l}$ of the vesicle solution was placed on Parafilm ${ }^{\circledR}$, and then a carbon coated copper grid was placed over the drop. After $30 \mathrm{~min}$, the modified grid was rinsed and placed onto a drop $(20 \mu \mathrm{l})$ of Fenton solution during 5 and $15 \mathrm{~min}$ in the absence of ascorbic acid, and $30 \mathrm{~min}$ in the presence of it. Finally, the grids were rinsed and dried under reduced pressure and stained with phosphotungstic acid $0.1 \%$ as contrast prior to placement in the microscope. 


\subsection{Procedures}

\subsubsection{Vesicles preparation}

The LUVs of DOPC were prepared by using an extrusion method [20], for this a stock lipid solution was prepared by measuring an appropriate amount of DOPC in chloroform (The phase transition temperature of DOPC is $-17.3^{\circ} \mathrm{C}$ ) [21]. After this, the solvent was evaporated and the film was dried under reduced pressure. Large multilamellar vesicles LMVs) were obtained by hydrating the dry lipid-dye film with PBS pH 7.4, through mixing (Vortex - 2-Genie) for about 5 min at room temperature. The resulting solution of LMVs provided the desire lipid concentration (1 $\mathrm{mg} \mathrm{mL}^{-1}$ ). To prepare large unilamellar vesicles (LUVs), the LMV suspension was extruded ten times (Extruder, Lipex biomembranes) through two stacked polycarbonate filters of pore size $200 \mathrm{~nm}$ under nitrogen pressure up to $3.4 \mathrm{~atm}$ [22]. All samples were used immediately after preparation. The LUV diameter, obtained from DLS measurements, was $190 \pm 2 \mathrm{~nm}$.

\subsubsection{Electrochemical assay procedure}

The electrochemical experiments consisted of four steps (Schematic 1): 1- DOPC LUV immobilization onto a CPE by immersion of the electrode in a DOPC LUV $\left(1 \mathrm{mg} \mathrm{mL}^{-1}\right)$ solution for a period of $30 \mathrm{~min}$ (time determined experimentally for optimal coating), 2- surface coating check by SWV in a cell containing $\left[\mathrm{Fe}(\mathrm{CN})_{6}\right]^{4-}(4.0 \mathrm{mM})$ with PBS $\mathrm{pH} 7.4$ as support electrolyte, 3- exposure of adsorbed LUVs to hydroxyl radicals by immersion of the modified electrode in a freshly prepared Fenton mixture (HO• generation) for a fixed period of reaction time, in the absence of antioxidant (induction of damage) and in the presence of antioxidant (protective effect), 4- SWV in a cell containing $\left[\mathrm{Fe}(\mathrm{CN})_{6}\right]^{4-}$ $(4.0 \mathrm{mM})$ after exposure to radicals, to evaluate oxidative damage produced in adsorbed LUVs in the absence of AA (ascorbic acid), and the protective effect in presence of AA, by changes in the SWV net peak current $\left(\mathrm{i}_{\mathrm{pn}}\right)$. The electrode was rinsed with Mili-Q before and after every step.

For the electrochemical studies the oxidation peak current $\left(I_{p n}\right)$ of the $\left[\mathrm{Fe}(\mathrm{CN})_{6}\right]^{4-}$ was used as the reference electrochemical signal. Voltammograms of the different stages were registered: vesicle-modified

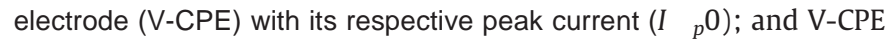
after exposure to radicals (Fenton solution) in the absence $\left(I_{p} d\right)$ or in the presence of the AA antioxidant $\left(I_{p} a\right)$. Each analysis was performed three to six times.

\section{Results and discussion}

3.1. Vesicles-modified electrode construction and its characterization using electrochemical techniques

In order to verify the DOPC LUV immobilization efficiency onto the $\mathrm{CPE}$, electrochemical characterization was performed. For this, a bare CPE or a V-CPE was immersed in PBS buffer at pH 7.4 and CVs were obtained over the potential range $-0.15 \mathrm{~V}$ to $+1.0 \mathrm{~V} \mathrm{vs}$. $\mathrm{Ag} / \mathrm{AgCl}$. As seen in Fig. 1 the background current of the electrolyte obtained for the VCPE was higher than that of the bare CPE. This electrochemical behaviour can be explained by the capacitive current generated by the DOPC LUVs that were physically adsorbed onto the CPE surface.

SWV, a more sensitive voltammetric technique, was used for characterization of the electrochemical process since it provides better quantitative measurements [22]. SWV of electroactive species, namely $\left[\mathrm{Fe}(\mathrm{CN})_{6}\right]^{4-}$, is a valuable tool for testing the kinetic barrier of the interface, because the electron transfer between the solution species and the electrode must occur through barriers defects. Thus, the redox complex $\left[\mathrm{Fe}(\mathrm{CN})_{6}\right]^{4-}$ was chosen as electroactive marker to investigate changes in electrode surface behaviour after each DOPC LUV $\left(1 \mathrm{mg} \mathrm{mL}^{-1}\right.$, average size of $190 \mathrm{~nm}$ ) immobilization step. The anodic peaks presented in Fig. 2 were obtained from the $\left[\mathrm{Fe}(\mathrm{CN})_{6}\right]^{4-}(4.0 \mathrm{mM})$ in PBS as support electrolyte. As it is possible to verify, at $+0.56 \mathrm{~V} \mathrm{vs} \mathrm{Ag} / \mathrm{AgCl}$ a signal appears with a peak intensity $\left(I_{p} 0\right)$ of $6.68 \mu \mathrm{A}$ when a bare CPE is used. The same experiment was performed by using a V-CPE, and a slight displacement of the $\left[\mathrm{Fe}(\mathrm{CN})_{6}\right]^{4-}$ redox potential was observed (at $+0.63 \mathrm{~V}$ vs $\mathrm{Ag} / \mathrm{AgCl}$ ). Fig. 3 displays the effect of the DOPC LUV immobilization time on the electrochemical response to $\left[\mathrm{Fe}(\mathrm{CN})_{6}\right]^{4-} 4.0 \mathrm{mM}$ in PBS $\mathrm{pH}$ 7.4. The anodic peak of the $\left[\mathrm{Fe}(\mathrm{CN})_{6}\right]^{4-}$ decreased rapidly when the CPE was immersed in DOPC LUV $\left(1 \mathrm{mg} \mathrm{mL}^{-1} ; 190 \pm 2 \mathrm{~nm}\right)$,

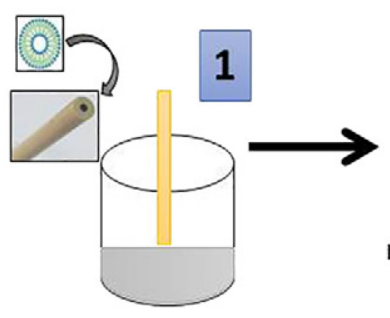

30 min in LUV solution.

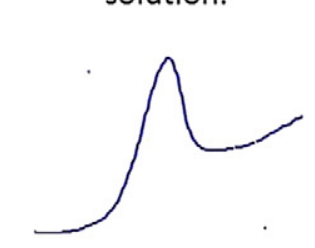

Evaluation of damage and

antioxidant protection by changes in ip

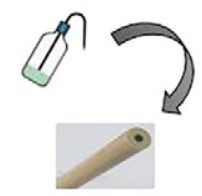

rinse with water

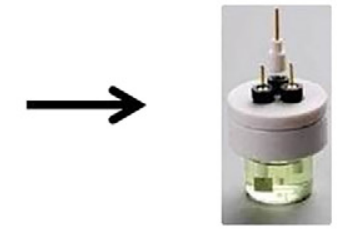

Electrochemical cell containing $\left[\mathrm{Fe}(\mathrm{CN})_{6}\right]^{4-}$ in PBS pH 7.4

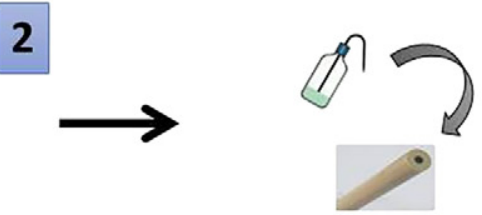

rinse with water

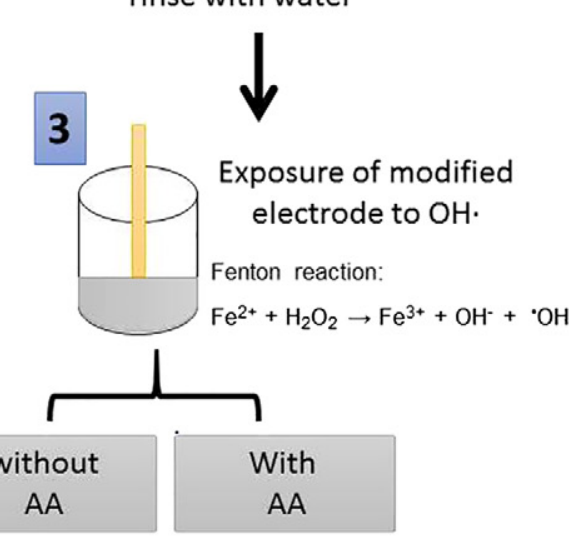

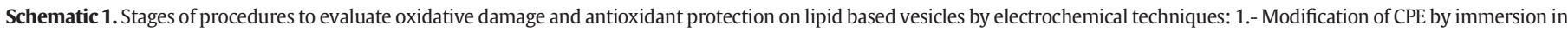

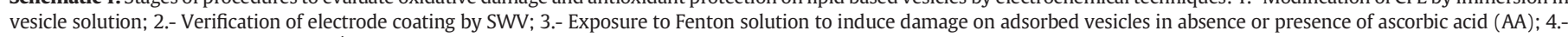
Electrochemical detection of $\left[\mathrm{Fe}(\mathrm{CN})_{6}\right]^{4-}$ solution to evaluate changes in surface coating as consequence of oxidative damage. Electrode was washed out before and after each step. 


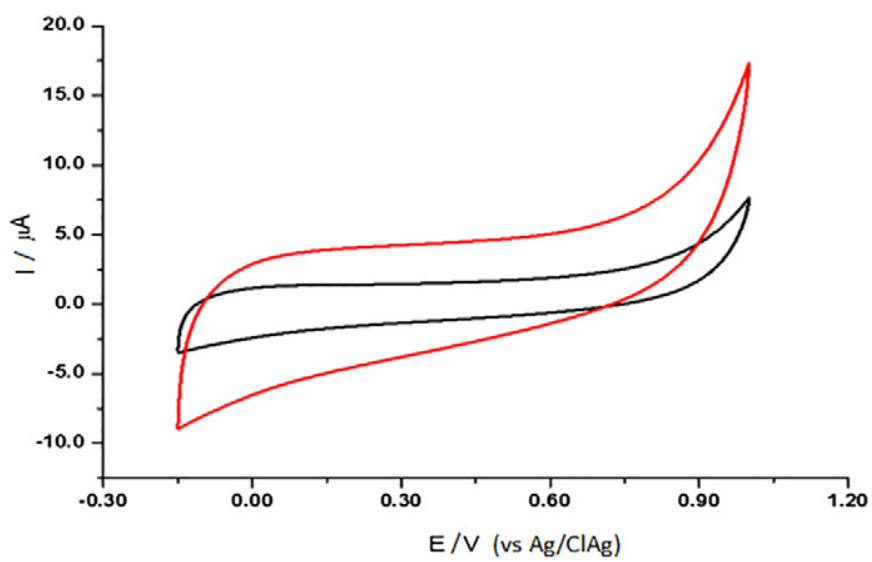

Fig. 1. Cyclic voltammograms of a carbon paste electrode in: a) PBS pH 7.4; b) after immersion $30 \mathrm{~min}$ in DOPC LUV solution (DOPC $1 \mathrm{mg} \mathrm{ml}^{-1}$; average size $190 \pm 2 \mathrm{~nm}$ ) $\mathrm{v}=100 \mathrm{mV} \mathrm{s}^{-1}$.

within 2 min, and gradually become constant after $30 \mathrm{~min}$. 46.7\% electrochemical signal inhibition $\left(I_{p}\right.$ decrease) was obtained for the CPE after 30 min in contact with the DOPC LUV. These results clearly demonstrate that DOPC LUVs were effectively immobilized onto the CPE surface, moreover the immobilized vesicles appear to block the diffusion of the $\left[\mathrm{Fe}(\mathrm{CN})_{6}\right]^{4-}$ towards the CPE surface and gradually decrease the current response. Consequently, a DPOC LUV immobilization time of 30 min was chosen for further experiments.

Considering that the vesicles (DOPC LUV) are spheres with an average diameter of $1.90 \times 10^{-5} \mathrm{~cm}(190 \pm 2 \mathrm{~nm})$ and the calculated electroactive area was $0.0525 \mathrm{~cm}^{2}$ for a bare CPE, it was possible to estimate the total number of vesicles immobilized onto CPE surface after $30 \mathrm{~min}$ of immobilization. When one LUV is adsorbed on the surface, the occupied area corresponds to that of a disk $\left(A=\pi r^{2}\right)$ with $r=9.5$ $\times 10^{-6} \mathrm{~cm}$. The total electroactive area of the bare electrode is $0.0525 \mathrm{~cm}^{2}$. After LUV immobilization, according to the detected signal, the new electroactive area is $0.0295 \mathrm{~cm}^{2}$; therefore the area occupied by the vesicles was $0.023 \mathrm{~cm}^{2}$. Consequently, the number of vesicles adsorbed in $30 \mathrm{~min}$ of modification was around $0.81 \times 10^{8}$ vesicles.

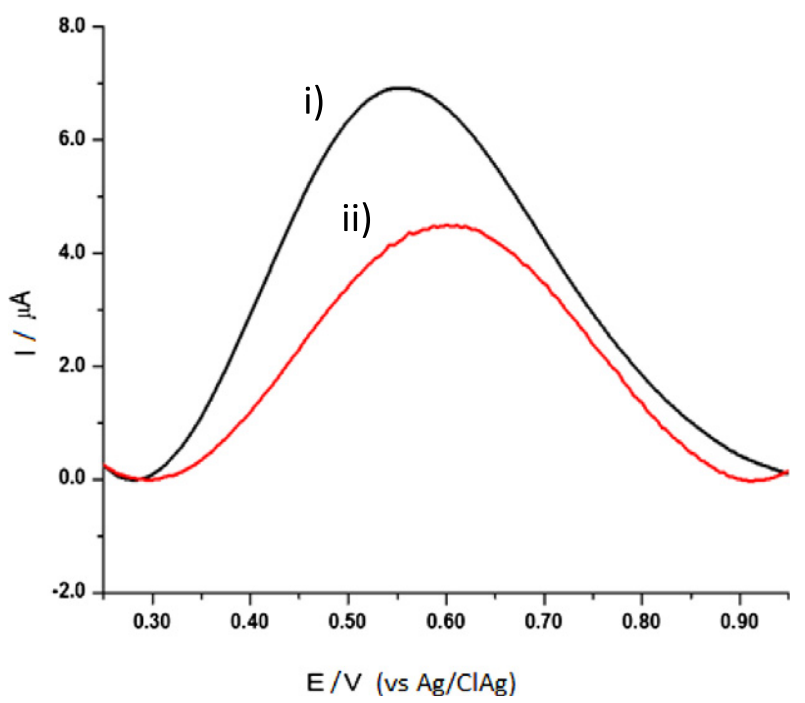

Fig. 2. Square wave voltammograms of $\left[\mathrm{Fe}(\mathrm{CN})_{6}\right]^{4-} 4.0 \mathrm{mmol}^{-1}$ in $\mathrm{PBS} \mathrm{pH} 7.4$ at i) bare $\mathrm{CPE}$ and ii) vesicle-modified electrode with modification time of $10 \mathrm{~min}$ in DOPC LUV solution. $\Delta \mathrm{E}_{\mathrm{SW}}=0.025 \mathrm{~V} ; \Delta \mathrm{E}_{\mathrm{s}}=0.005 \mathrm{~V}, \mathrm{f}=20 \mathrm{~Hz}$.

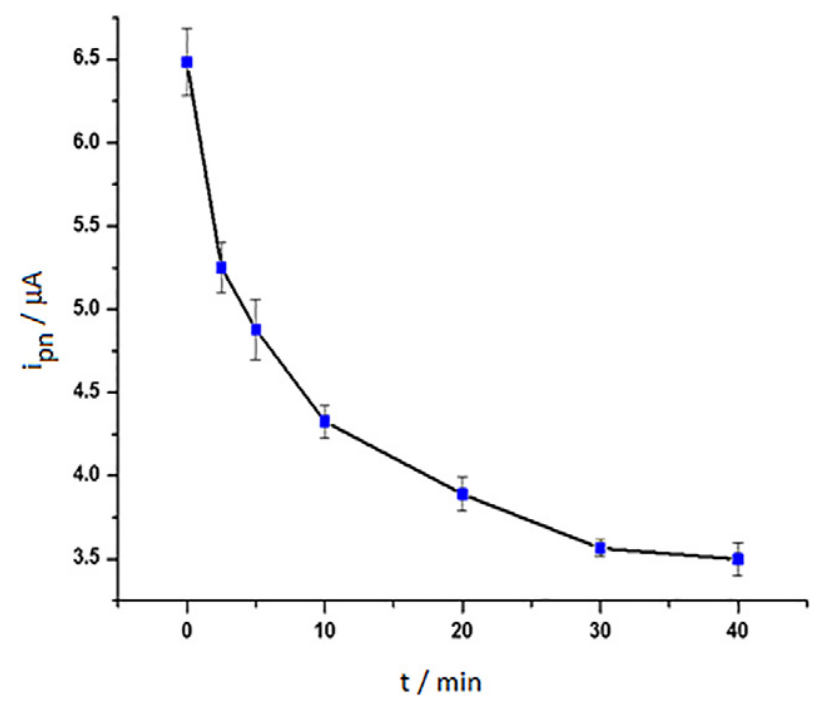

Fig. 3. Effect of the different $\mathrm{V}-\mathrm{CPE}$ at different immersion times on net peak current $\left(\mathrm{i}_{\mathrm{pn}}\right)$ of the square wave voltammograms for $\left[\mathrm{Fe}(\mathrm{CN})_{6}\right]^{4-} 4.0 \mathrm{mmol}^{-1}$ in $\mathrm{PBS} \mathrm{pH}$ 7.4. $\Delta \mathrm{E}_{\mathrm{SW}}=$ $0.025 \mathrm{~V} ; \Delta \mathrm{E}_{\mathrm{s}}=0.005 \mathrm{~V}, \mathrm{f}=20 \mathrm{~Hz}$.

3.2. Electrochemical behaviour of the vesicle-modified electrode in the presence of free radical and antioxidants

The most prevalent ROS that can profoundly affect lipids is the hydroxyl radical (HO•). This short-lived radical can be produced in cell metabolism and under a variety of stress conditions. It is generally assumed that in biological systems is formed through redox cycling by the Fenton reaction, where free iron $\left(\mathrm{Fe}^{2+}\right)$ reacts with hydrogen peroxide $\left(\mathrm{H}_{2} \mathrm{O}_{2}\right)$ [24]. Actually, cells are able to produce around 50 hydroxyl radicals every second. In a full day, each cell would generate 4 million hydroxyl radicals, which can be neutralized or attack biomolecules, such as those in the cell membrane [25].

To confirm whether the hydroxyl radical, generated by the Fenton reaction, exhibits the ability to induce oxidative lesions in the vesicles immobilized on the CPE (simulating the cellular membrane), SW voltammograms were registered before (Fig. 4a i) and after (Fig. 4a i-iv) the immersion of the V-CPE in the solution containing free radicals.

The V-CPE was placed in a freshly prepared solution of $\mathrm{HO} \bullet$ in PBS $\mathrm{pH} 7.4$ for $5 \mathrm{~min}$. After this process, the V-CPE was washed and taken to the electrochemical cell, where a SWV was recorded from +0.3 to $+1.0 \mathrm{~V}$ using the redox complex $\left[\mathrm{Fe}(\mathrm{CN})_{6}\right]^{4-}$ as electrochemical label. $\mathrm{HO} \cdot$ was observed to induce oxidative damage on the DOPC LUV. Actually, when the DOPC LUVs immobilized on the CPE interacted with the hydroxyl radical, an increase in the oxidation peak of the $\left[\mathrm{Fe}(\mathrm{CN})_{6}\right]^{4-}$ was observed (Fig. 4a ii). The same procedure was performed at different times (15 min and $30 \mathrm{~min}$ ) (Fig. 4a iii and iv). It was verified that at 30 min the current recorded was of the order of the current obtained for an unmodified electrode. This would indicate that at this time the maximum damage has occurred in the bilayer. As reported in the literature, lipid peroxidation has the facility to perturb the bilayer structure and to modify the membrane properties such as membrane fluidity, permeability to different substances and bilayer thickness [26]. Thereby, it is possible to consider that the $\mathrm{HO} \cdot$ used to induce oxidative lesions in the DOPC LUV, generated phospholipid radicals, changing the bilayer, increasing permeability and eventually destroying the lipid membrane; these events promoted an increase of electron transfer between the solution and the electrode which led to an increased electrochemical response. Fig. $4 \mathrm{~b}$ shows the performance of the V-CPE in the presence of the hydroxyl radical. As it is possible to verify, after 5 min incubation time, the $\mathrm{HO}$ produced $30 \%$ damage in the vesicles immobilized on the CPE (Considering that $100 \%$ of damage corresponds to the difference 
a)

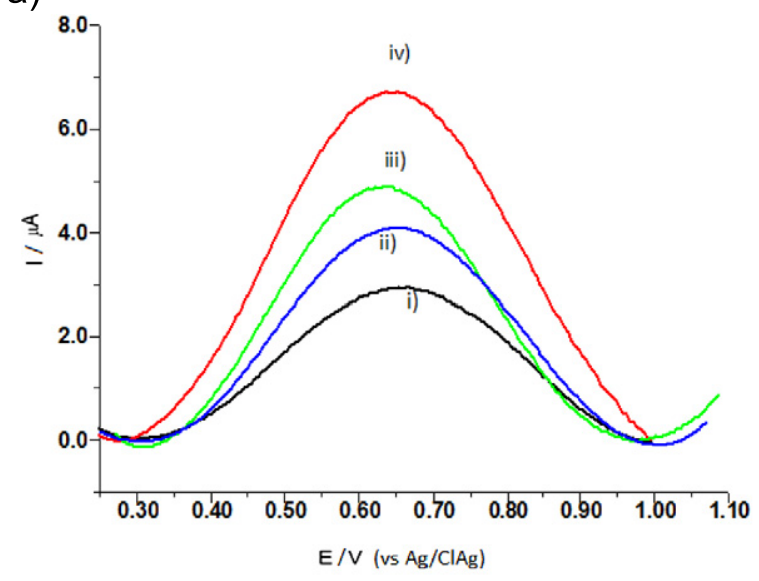

b)

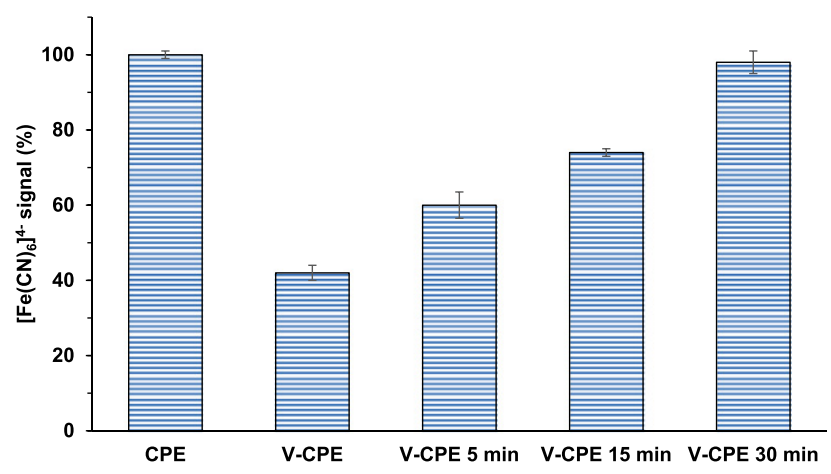

Fig. 4. a) SWV of $\left[\mathrm{Fe}(\mathrm{CN})_{6}\right]^{4-} 4.0 \mathrm{mM}$ in PBS pH 7.4 at (i) V-CPE with modification time of $30 \mathrm{~min}$ in DOPC LUV solution; and after immersion the V-CPE in a hydroxyl radical (Fe(II) $=1 \times 10^{-4} \mathrm{moll}^{-1} ; \mathrm{EDTA}=2 \times 10^{-4} \mathrm{moll}^{-1} ; \mathrm{H}_{2} \mathrm{O}_{2}=4 \times 10^{-3} \mathrm{moll}^{-1}$ solution during (ii) $5 \mathrm{~min}$; (iii) $15 \mathrm{~min}$ and (iv) $30 \mathrm{~min}$; b) $\left.\mathrm{Fe}(\mathrm{CN})_{6}\right]^{4-} 4 \mathrm{mmol} \mathrm{l}^{-1}$ signal percentage on bare CPE and V-CPE. Experimental conditions as item a).

in response obtained at an unmodified electrode and that obtained at the modified electrode with DOPC LUV). Increasing the interaction time between the free radical and the V-CPE the oxidation peak increased, which implies an increase of the percentage damage. Actually, $78 \%$ and $99 \%$ was obtained for $\left[\mathrm{Fe}(\mathrm{CN})_{6}\right]^{4-}$ signal percentage when an exposure time of 15 and 30 min to Fenton solution was used, respectively. As expected, increasing exposure time results in more oxidative lesions on the vesicles and an increment of electroactive area. So, the diffusion rate of the $\left[\mathrm{Fe}(\mathrm{CN})_{6}\right]^{4-}$ from the solution to the electrode surface gradually increases the peak intensity when $\mathrm{V}$-CPE is obtained in the electrochemical cell. An exposure time of 15 min to the Fenton solution was chosen for the further experiments. Using $15 \mathrm{~min}$ it is possible to induce vesicles oxidative damage, but without complete damage.

Under physiological lipid peroxidation processes, cells stimulate their maintenance and survival through constitutive antioxidants defence systems [25]. In order to prove antioxidant ability as being due to free radical scavenging, ascorbic acid (AA) was used as the antioxidant model. Indeed, the protective action of antioxidants may involve multiple mechanisms, depending on the source material and possible presence of synergists and antagonists. In general, the antioxidant activity of the AA is related to reducing properties such as hydrogen and electron donation, which is related to its reduction potential [17].

When an AA solution of $220 \mu \mathrm{mol} \mathrm{l}^{-1}$ was added to the reactive system (composed of $\mathrm{HO} \cdot$ ) and $\mathrm{V}-\mathrm{CPE}$ was exposed to it over $15 \mathrm{~min}$ (see Schematic 1, step 3), a lower increase in the anodic current of the $\left[\mathrm{Fe}(\mathrm{CN})_{6}\right]^{4-}$ was registered in comparison with the current observed in the absence of AA, and a protective effect of $68.3 \%$ was observed (Fig. 5)

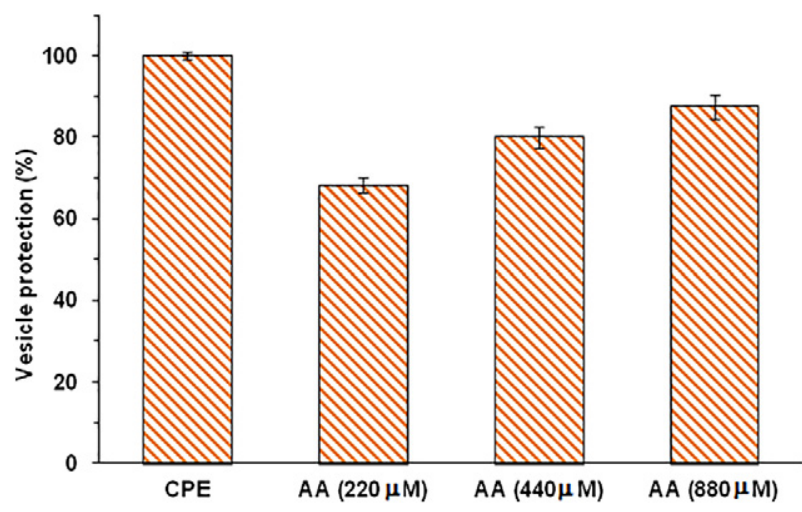

Fig. 5. Influence of the ascorbic acid antioxidant concentration on the vesicle integrity protection (incubation time 15 min in Fenton solution: $\mathrm{Fe}(\mathrm{II})=1 \times 10^{-4} \mathrm{~mol}^{-1}$; EDTA $\left.=2 \times 10^{-4} \mathrm{~mol} \mathrm{l}^{-1} ; \mathrm{H}_{2} \mathrm{O}_{2}=4 \times 10^{-3} \mathrm{~mol} \mathrm{l}^{-1}\right)$. V-CPE with modification time of $30 \mathrm{~min}$ in DOPC LUV solution.

(considering that the percentage of protection $=100$ - percentage of damage). These observations confirm the ability of the antioxidant AA to deactivate the hydroxyl radical and the newly generated lipid and lipid peroxyl radical.

To further examine the protective properties of the AA, the $\mathrm{V}-\mathrm{CPE}$ was immersed in Fenton solution with different AA concentrations for 15 min (Fig. 5). Experimental results showed that the electrochemical response of the $\mathrm{V}$-CPE was related to the amount of AA presents in the reaction medium. As the concentration of $A A$ increases the electrochemical signal decreases, which indicates the protective role of AA in the prevention of oxidative damage to LUV. Indeed, when an AA concentration of $440 \mu \mathrm{mol} 1^{-1}$ or $880 \mu \mathrm{mol} \mathrm{l}^{-1}$ was used, the protection percentage was 80 and $87.5 \%$, respectively.

At low lipid peroxidation rates, the cells stimulate their maintenance through antioxidant defence systems, but by contrast, under medium or high lipid peroxidation rates the extent of oxidative damage overwhelms repair capacity and the cells induce apoptosis [26].

So, the protective effect of the AA antioxidant against lipid oxidation of vesicles immobilized onto CPE with different hydroxyl radical concentrations $\left(1 ; 10,20,100\right.$ and $\left.200 \mu \mathrm{mol} \mathrm{l}^{-1}\right)$ was also studied. Fig. 6 shows the experimental results obtained from this study in the presence and absence of AA. As can be seen at constant AA concentration,

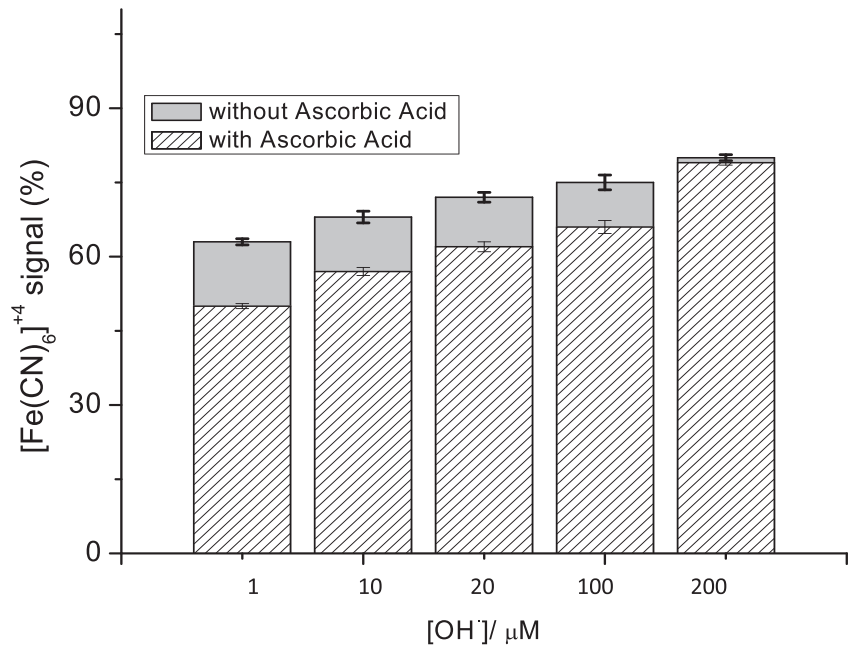

Fig. 6. $\left.\mathrm{Fe}(\mathrm{CN})_{6}\right]^{4-} 4 \mathrm{mmol} \mathrm{l}^{-1}$ in PBS $\mathrm{pH} 7.4$ signal percentage on vesicle-modified electrode without and with AA $\left(440 \mu \mathrm{mol} \mathrm{l}^{-1}\right)$. Influence of the $\mathrm{HO} \cdot$ concentration. VCPE with modification time of $30 \mathrm{~min}$ in DOPC LUV solution. Incubation time $15 \mathrm{~min}$ in Fenton solution: $\mathrm{Fe}(\mathrm{II})=1 \times 10^{-4} \mathrm{~mol} \mathrm{l}^{-1}$; EDTA $=2 \times 10^{-4} \mathrm{~mol} \mathrm{l}^{-1} ; \mathrm{H}_{2} \mathrm{O}_{2}=4$ $\times 10^{-3} \mathrm{~mol} \mathrm{l}^{-1}$. 


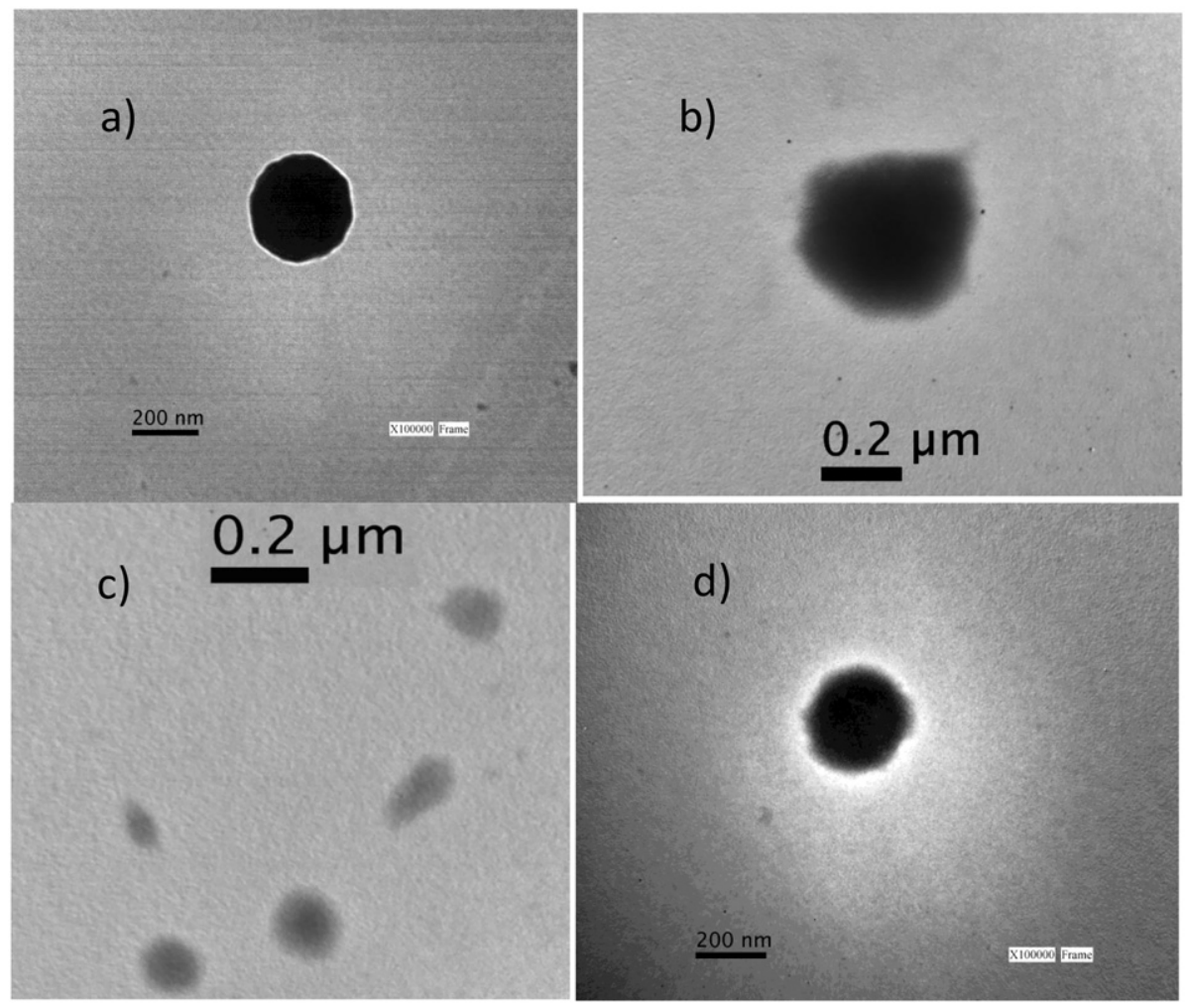

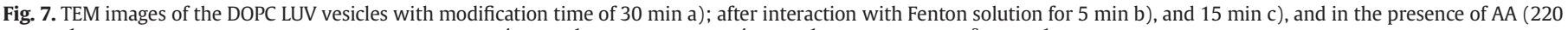
$\mu \mathrm{mol} \mathrm{l}^{-1}$ ) for $30 \mathrm{~min}$ d). Fenton solution: $\mathrm{Fe}(\mathrm{II})=1 \times 10^{-4} \mathrm{~mol} \mathrm{l}^{-1}$; EDTA $=2 \times 10^{-4} \mathrm{~mol} \mathrm{l}^{-1} ; \mathrm{H}_{2} \mathrm{O}_{2}=4 \times 10^{-3} \mathrm{~mol} \mathrm{l}^{-1}$.

as $\mathrm{HO} \bullet$ increases, the differences between $\mathrm{V}$-CPE in presence and absence of $\mathrm{AA}$, of the $\left[\mathrm{Fe}(\mathrm{CN})_{6}\right]^{4-}$ signal percentage decreases. In other words, the protective effect of AA decreases with the increase of $\mathrm{HO}$. Up to a value of $100 \mu \mathrm{M}$ of $\mathrm{HO} \cdot$, a protective effect of $\mathrm{AA}$ is observed, but from $200 \mu \mathrm{M}$ of $\mathrm{HO} \cdot$, AA does not provide protection, and there is no difference in the signal obtained in the presence and absence of AA. This behaviour confirms the data reported in the literature [24-26].

\subsection{Morphologic characterization of LUV}

One important parameter for the vesicle-modified electrode is the morphology, size and distribution of the vesicles on the CPE surface. From the DLS technique, the diameter and polydispersity of DOPC LUVs was measured. It was observed that the DOPC LUVs presented a diameter of $190 \pm 2 \mathrm{~nm}$ and a polydispersity of 0.129 . Changes in vesicle structure and integrity were observed when the vesicles were incubated in hydroxyl radical. It was verified that the polydispersity index shifted to 0.703 and 1.0 when the vesicles interacted with the hydroxyl radical for 15 or $60 \mathrm{~min}$, respectively. Moreover, the observed changes in the polydispersion values indicated that the hydroxyl radical perturbed the bilayer structure modifying its properties, size and shape.

Fig. 7 shows TEM images before and after the immersion of the vesicle-modified carbon-coated copper grid in the reaction media (containing free radical with or in the absence AA). From Fig. 7a it is clearly observed that the DOPC LUVs present a spherical structure with a size around of $193 \mathrm{~nm}$. From comparison images 7a to 7d it is possible to detect obvious differences in the morphology of the vesicles. In fact, when the DOPC LUVs did not interact with the free radical (Fig. 7a), the spherical structure was retained. However, when the vesicles were incubated with the hydroxyl radical for 5 or 15 min (Fig. 7b and c), the DOPC LUV spherical structure was not retained and modification on the DOPC LUV morphology, size and shape and destruction of the bilayer was observed. In fact, the observed behaviour explains the electrochemical results. Destruction of the vesicles immobilized on V-CPE promote an increment of electroactive area with the consequence of rapid and easy $\left[\mathrm{Fe}(\mathrm{CN})_{6}\right]^{4-}$ diffusion to the electrode surface increasing peak intensity.

When AA was added to the reaction system, the DOPC LUVs retained their original structure even after $30 \mathrm{~min}$ (Fig. 7d), confirming the protective effect of AA, It should be noted that in the absence of AA at $30 \mathrm{~min}$ it was not possible to find an undamaged vesicle. These studies again confirm the results obtained from electrochemical techniques.

\section{Conclusion}

In this work an electrochemical strategy is developed for the first time which can be used as an efficient analytical tool to investigate lipid peroxidation and antioxidant protection against lipid oxidative damage. To perform this study DOPC LUVs were used to simulate cell membranes, $\mathrm{HO}$ - generated via the Fenton reaction as cellular free radicals and AA as antioxidant model. The experiments were carried out by immobilization DOPC LUV onto CPE surface. Using SWV it was possible to confirm the capability of the $\mathrm{HO} \cdot$ to induce oxidative lesion onto $\mathrm{V}$ $\mathrm{CPE}$ and the ability of the $\mathrm{AA}$ as $\mathrm{HO} \bullet$ scavenger to defend vesicles from the oxidative lesions. Additionally, TEM analysis provided reasonable interpretation confirming the electrochemical results. The developed methodology presents several advantages such as speed, simplified assay and reproducibility.

\section{Acknowledgment}

This work was financial supported by Consejo Nacional de Investigaciones Científicas y Técnicas (CONICET), Universidad Nacional de Río Cuarto, and Agencia Nacional de Promoción Científica y Técnica, Marie Curie Actions, International Research Staff Exchange Scheme FP7PEOPLE-2013-IRSES (612545), and by the European Union (FEDER funds through COMPETE) and National Funds (FCT-Fundação para a Ciência e a Tecnologia) through UID/QUI/50006/2013 and through 
grants no. PEst-C/EQB/LA0006/2013 and FCOMP-01-0124-FEDER037285. Fátima Barroso is grateful to FCT by the grant SFRH/BPD/ 78845/2011, respectively financed by POPH-QREN-Tipologia 4.1Formação Avançada, subsidized by Fundo Social Europeu and Ministério da Ciência, Tecnologia e Ensino Superior.is gratefully acknowledged. M. A. L. thanks from CONICET for a research post-doctoral fellowship.

\section{References}

[1] M.F. Barroso, N. de-los-Santos-Álvarez, M.J. Lobo-Castañón, A.J. Miranda-Ordieres, C. Delerue-Matos, M.B.P.P. Oliveira, P. Tuñón-Blanco, DNA-based biosensor for the electrocatalytic determination of antioxidant capacity in beverages, Biosens. Bioelectron. 26 (2011) 2396-2401.

[2] M.F. Barroso, N. de-los-Santos-Álvarez, C. Delerue-Matos, C.M.B.P.P. Oliveira, Towards a reliable technology for antioxidant capacity and oxidative damage evaluation: electrochemical (bio)sensors, Biosens. Bioelectron. 30 (2011) 1-12.

[3] K.A. Freidman, A. Heller, Guanosine distribution and oxidation resistance in eight eukaryotic genomes, J. Am. Chem. Soc. 126 (126) (2004) 2368-2371.

[4] G. Lyu, G. Shi, L. Tang, H. Fang, M. Wu, Mechanism of degradation of a nitrogenous heterocycle induced by a reductive radical: decomposition of a sym-triazine ring, Phys. Chem. Chem. Phys. 19 (2017) 9354-9357.

[5] M. Repetto, J. Semprine, in: Angel Catala (Ed.), A Boveris, Lipid Peroxidation: Chemical Mechanism, Biological Implications and Analytical Determination, in Lipid Peroxidation, Chapter 1, 2012 (ISBN 978-953-51-0716-3).

[6] D.K. Vessela, O.T. Kasaikina, in: Angel Catala (Ed.), Lipid Oxidation in Homogeneous and Micro-heterogeneous Media in Presence of Prooxidants, Antioxidants and Surfactants in Lipid Peroxidation, Chapter 2, 2012 (ISBN 978-953-51-0716-3).

[7] H.A.H.M.A. El-Aal, in: Angel Catala (Ed.), Lipid Peroxidation End-products as a Key of Oxidative Stress: Effect of Antioxidant on Their Production and Transfer of Free Radicals. In Lipid Peroxidation, Chapter 3, 2012 (ISBN 978-953-51-0716-3).

[8] S.A. Kelly, C.M. Havrilla, T.C. Brady, K.H. Abramo, E.D. Levin, Oxidative stress in toxicology: established mammalian and emerging piscine model systems, Environ. Health Perspect. 106 (1998) 375-384.

[9] A.R. Waldeck, R. Stocker, Radical-initiated lipid peroxidation in low density lipoproteins: insights obtained from kinetic modeling Chem. Res. Toxicol. 9 (1996) 954-964

[10] G. Şener, K. Paskaloğlu, H. Toklu, C. Kapucu, G. Ayanoglu-Dulger, A. Kacmaz, A. Sakarcan, Melatonin ameliorates chronic renal failure-induced oxidative organ damage in rats, J. Pineal Res. 36 (2004) 232-241.
[11] M. Laguerre, E.A. Decker, J. Lecomte, P. Villeneuve, Methods for evaluating the potency and efficacy of antioxidants, Curr. Opin. Clin. Nutr. Metab. Care 13 (2010) 518-525.

[12] P. Boonnoy, M. Karttunen, J. Wong-ekkabut, Alpha-tocopherol inhibits pore formation in oxidized bilayers, Phys. Chem. Chem. Phys. 19 (2017) 5699-5704.

[13] E. Anouar, P. Košinová, D. Kozlowski, R. Mokrini, J.L. Duroux, P. Trouillas, New aspects of the antioxidant properties of phenolic acids: a combined theoretical and experimental approach, Phys. Chem. Chem. Phys. 11 (2009) 7659-7668.

[14] P.M. Abuja, R. Albertini, Methods for monitoring oxidative stress, lipid peroxidation and oxidation resistance of lipoproteins, Clin. Chim. Acta 306 (2001) 1-17.

[15] R.A. Wheatle, Some recent trends in the analytical chemistry of lipid peroxidation, Trends Anal. Chem. 19 (2000) 617-628.

[16] R. Hu, M. Guille, S. Arbault, C.J. Lin, C. Amatore, et al., Phys. Chem. Chem. Phys. 12 (2010) 10048-10054.

[17] L.D. Mello, S. Hernandez, G. Marrazza, M. Mascini, T. Kubota, Investigations of the antioxidant properties of plant extracts using a DNA-electrochemical biosensor, Biosens. Bioelectron. 21 (2006) 1374-1382.

[18] J.C. Imbeaux, J.M. Savéant, Convolutive potential sweep voltammetry: I. Introduction, J. Electroanal. Chem. 44 (1973) 169-187.

[19] R.A. Mackay, S.A. Myers, L. Bodalbhai, A. Brajter-Toth, Microemulsion structure and its effect on electrochemical reactions, Anal. Chem. 62 (1990) 1082-1090.

[20] L.D. Mayer, M.J. Hope, P.R. Cullis, Vesicles of variable sizes produced by a rapid extrusion procedure, Biochim. Biophys. Acta 858 (1986) 161-168.

[21] N.M. Correa, Z.A. Schelly, Electroporation of unilamellar vesicles studied by using a pore-mediated electron-transfer reaction, Langmuir 14 (1998) 5802-5805.

[22] J.S.F. Tabares, M.L. Blas, L.E. Sereno, J.J. Silber, N.M. Correa, P.G. Molina, Electrochemistry in large unilamellar vesicles. The distribution of 1-naphthol studied by square wave voltammetry, Electrochim. Acta 56 (2011) 10231-10237.

[24] C. Schneider, W.E. Boeglin, H. Yin, N.A. Porter, A.R. Brash, Intermolecular peroxyl radical reactions during autoxidation of hydroxy and hydroperoxy arachidonic acids generate a novel series of epoxidized products, Chem. Res. Toxicol. 21 (2008) 895-903.

[25] A. Ayala, M.F. Muñoz, S. Argüelles, Lipid peroxidation: production, metabolism, and signaling mechanisms of malondialdehyde and 4-hydroxy-2-nonenal, Oxidative Med. Cell. Longev. (2014) (2014) (Article ID 360438, 31 pp.).

[26] J. Wong-ekkabut, Z Xu, W. Triampo, I-M. Tang, D.P. Tieleman, L. Monticelli, Effect of lipid peroxidation on the properties of lipid bilayers: a molecular dynamics study, Biophys. J. 93 (2007) 4225-4236. 